\title{
GIỚI THIỆU MÁY ĐO TRỌNG LỰC HÀNG KHÔNG TAGS AIR III VÀ ĐỀ XUÂTT QUY TRÌNH VẬN HÀNH BAY KHẢO SÁT TRỌNG LỬC Ở VIÊTT NAM
}

ThS. NGUYẼN TUÂN ANH, TS. DƯƠNG CHÍ CÔNG, KS. NGUYẼ̃N TRỌNG HIÉU, KS. VŨ TRUNG THÀNH

Viện Khoa học Đo đạc và Bản đồ

\section{Giới thiệu chung}
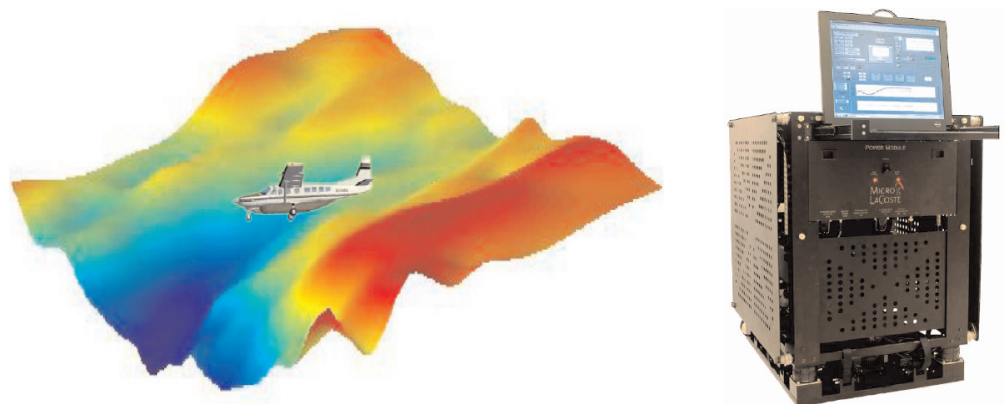

Hình 1: Máy đo Trọng lực Hàng không TAGS Air III

Máy đo trọng lực TAGS AIR III (Turnkey Airborne Gravity System) là bản nâng cấp từ hệ thống quan sát trên biển bằng máy bay của hãng LaCoste, được thiết kế đặc biệt cho hoạt động trên không. Hệ thống kết hợp chặt chẽ giữa thiết bị kiểm tra thời gian, độ trễ, trôi điểm 0 và bệ máy con quay hồi chuyển.

TAGS AIR III là máy đo trọng lực có độ tin cậy và độ chính xác cao. Các dữ liệu thô ở dạng số thu được từ các tuyến bay có thể được xử lý ngay lập tức để xác định dị thường trọng lực. Dứ liệu qua xử lý có thể được xuất ra thành các gói dữ liệu đầu vào cho các phần mềm ứng dụng như: Geosoft Oasis Montaj ${ }^{\mathrm{TM}}$ hay Generic Mapping Tools để phục vụ cho từng nhiệm vụ cụ thể như thành lập bản đồ dị thường trọng lực, thủy văn, địa chất và địa động lực .v.v...

Ngày 25 tháng 12 năm 2013 Viện Khoa học Đo đạc và Bản đồ đã nhập về hệ thống đo trọng lực hàng không TAGS-6 trong khuôn khổ Dự án đầu tư "Tăng cường thiết bị công nghệ phục vụ nghiên cứu khoa học Viện Khoa học Đo đạc và Bản đồ". Đây là hệ thống được nâng cấp mới nhất (trong hơn 10 đặc tính vận hành và cấu tạo) từ TAGS AIR III của hãng Micro-g LaCoste. TAGS-6 có biên độ trị đo, độ ổn định của bệ máy rộng hơn, khả năng lặp lại tĩnh được cải thiện, kích thước và trọng lượng giảm được một nửa, sử dụng tiết kiệm năng lượng điện hơn so với TAGS AIR III.

Hai hệ thống đo trọng lực nói trên đều có chung nguyên lý hoạt động và quy trình vận hành nhưng trên thực tế thì TAGS AIR III đã được sử dụng thành công tại nhiều nước trên thế giới như Mỹ, Canada, Tây Âu, Nhật Bản, Australia... trong khảo sát đo đạc trọng lực chi tiết phục vụ trắc địa bản đồ và đa ngành đa lĩnh vực. Trên cơ sở như vậy và xuất phát từ nhu cầu thực tiễn hiện nay ở Việt Nam nội dung bài báo này sẽ đề cập đến các thành phần, nguyên lý hoạt động và quy trình vận hành cơ bản của hệ thống TAGS AIR III. Chắc chắn chúng sẽ được ứng dụng kịp thời trong đo đạc thử nghiệm và triển khai đo trọng lực hàng không đất liền và trên biển với hệ thống TAGS-6 của Viện Khoa học Đo đạc và Bản đồ. 


\section{Các tham số kỹ thuật và thành phần trang thiết bị của máy}

\subsection{Các tham số kỹ thuật cơ bản}

\begin{tabular}{|c|c|c|}
\hline Bộ phận & Thông số kỹ thuật & Giá trị \\
\hline Cảm biến & $\begin{array}{l}\text { Biên độ trị đo } \\
\text { Dịch chuyển điểm } 0\end{array}$ & $\begin{array}{l}20.000 \text { mGals } \\
3 \text { mGals/tháng hoặc ít hơn }\end{array}$ \\
\hline $\begin{array}{l}\text { Giới hạn cân } \\
\text { bằng của bệ máy }\end{array}$ & $\begin{array}{l}\text { Góc dao động chúc lên xuống } \\
\text { Góc dao động nghiêng }\end{array}$ & $\begin{array}{l} \pm 22 \text { độ } \\
\pm 25 \text { độ }\end{array}$ \\
\hline Hệ thống điều khiển & $\begin{array}{l}\text { Tần số ghi } \\
\text { Cổng đầu ra } \\
\text { Cổng vào/ra bổ sung }\end{array}$ & $\begin{array}{l}1 \mathrm{~Hz} \\
\text { RS-232 } \\
\text { Nhiệt độ điện } \\
\text { Nhiệt độ cảm biến } \\
\text { Áp lực cảm biến }\end{array}$ \\
\hline Hệ thống & $\begin{array}{l}\text { Độ phân giải } \\
\text { Khả năng lặp lại tĩnh } \\
\text { Độ chính xác } \\
-50.000 \mathrm{mGals} \text { gia tốc phương } \\
\text { nằm ngang } \\
-100.000 \mathrm{mGals} \text { gia tốc } \\
\text { phương nằm ngang } \\
-100.000 \mathrm{mGals} \text { gia tốc } \\
\text { phương thẳng đứng }\end{array}$ & $\begin{array}{l}0,01 \text { mGals } \\
0,05 \text { mGals } \\
1,0 \text { mGals hoặc cao hơn } \\
0,25 \text { mGals } \\
0,50 \text { mGals } \\
0,25 \text { mGals }\end{array}$ \\
\hline Các thông tin khác & $\begin{array}{l}\text { Nhiệt độ vận hành } \\
\text { Nguồn điện } \\
\text { Kích thước } \\
\text { Trọng lượng }\end{array}$ & $\begin{array}{l}5^{\circ} \mathrm{C}-50^{\circ} \mathrm{C} \\
\text { Trung bình } 240 \text { Oát } \\
80-265 \text { VAC, } 47-63 \mathrm{~Hz} 71 \times 56 \times \\
84(\mathrm{~cm}) \\
140 \mathrm{~kg}\end{array}$ \\
\hline
\end{tabular}




\subsection{Cấu tạo các thành phần thiết bị}

\begin{tabular}{|c|c|c|}
\hline STT & Bộ phận chính & Thành phần thiết bị \\
\hline 1 & Bộ cảm biến & $\begin{array}{l}\text { Bộ cảm biến } \\
\text { Thiết bị điều khiển } \\
\text { Bộ tản nhiệt }\end{array}$ \\
\hline 2 & Khớp cân bằng đa năng & $\begin{array}{l}\text { Khớp đa năng } \\
\text { Bộ giảm chấn không khí } \\
\text { Dây cáp p200 } \\
\text { Mô đun nguồn dự phòng } \\
\text { Mô đun điều khiển dự phòng } \\
\text { Thiết bị đo thời gian dự phòng } \\
\text { Động cơ tạo mô men xoắn } \\
\text { Bộ công cụ } \\
\text { Thiết bị ghi dữ liệu }\end{array}$ \\
\hline 3 & Khung giá đỡ & $\begin{array}{l}\text { Khung } \\
\text { Màn hình, bàn phím và chuột được gắn sã̃n trêr } \\
\text { khung } \\
\text { Mô đun nguồn chính } \\
\text { Mô đun điều khiển chính } \\
\text { Bộ lưu dòng (UPS) } \\
\text { Đế đỡ máy có đệm không khí chống rung } \\
\text { Dây cáp P1 } \\
\text { Dây cáp P100 } \\
\text { Thiết bị đo thời gian }\end{array}$ \\
\hline 4 & $\begin{array}{l}\text { Phụ tùng và phụ kiện } \\
\text { phụ trợ khác }\end{array}$ & $\begin{array}{l}\text { Giá đỡ cố định } \\
\text { Bộ lưu dòng UPS dự phòng } \\
\text { Bộ đổi nguồn điện máy bay } \\
\text { Giá ba chân GPS \& bộ kết nối } \\
\text { Thiết bị đo thời gian dưới mặt đất } \\
\text { Ăng ten GPS trạm mặt đất } \\
\text { Ăng ten GPS trên máy bay } \\
\text { Thiết bị con quay hồi chuyển dự phòng } \\
\text { Cáp TNC } \\
\text { Cáp nguồn AC } \\
\text { Bộ kết nối BNC }\end{array}$ \\
\hline
\end{tabular}




\subsection{Mô tả các thành phần thiết bị và cơ chế hoạt động}

2.3.a. Giá đỡ cố định

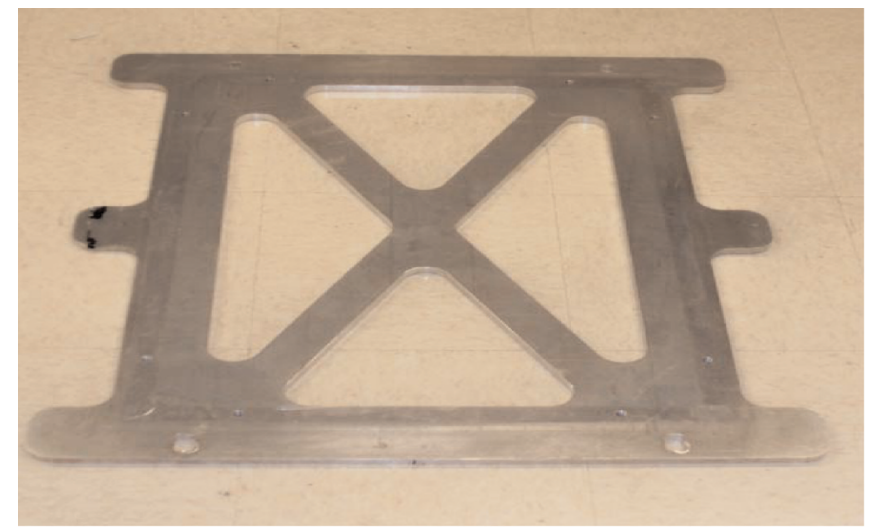

Hình 2: Giá đỡ cố định

Giá đỡ cố định được bắt vít vào đường ray ghế máy bay để cố định TAGS. Hầu hết máy bay có cấu hình đường ray ghế máy bay khác nhau nên không thể gắn kết trực tiếp TAGS đến đường ray ghế máy bay, do vậy phải gắn giá đỡ lên đường ray ghế máy bay sau đó mới gắn TAGS lên giá đỡ.

\section{3.b. Ăng ten GPS gắn trên máy bay}

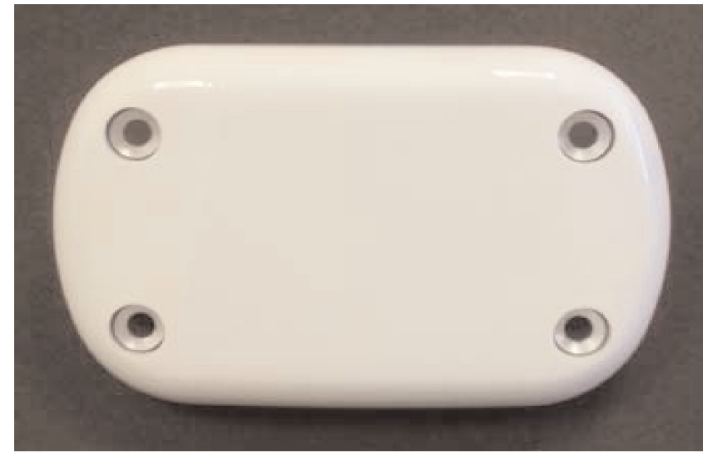

Mặt trên Ăng ten

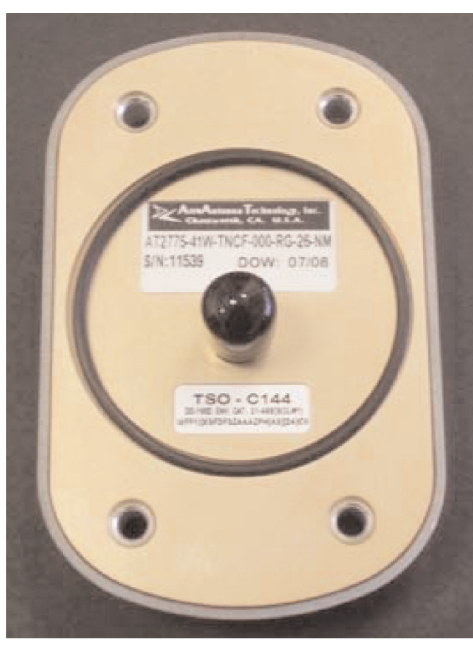

Mặt dưới Ăng ten

Hình 3: Ăng ten định vị trên máy bay

Ăng ten GPS được thiết kế chuyên dụng cho việc đo động và gắn chặt vào phần chính giữa nóc của thân máy bay. Ăng ten và máy thu có thiết bị đo thời gian của TAGS sử dụng bộ kết nối tiêu chuẩn TNC. 
2.3.c. Bộ đổi nguồn điện

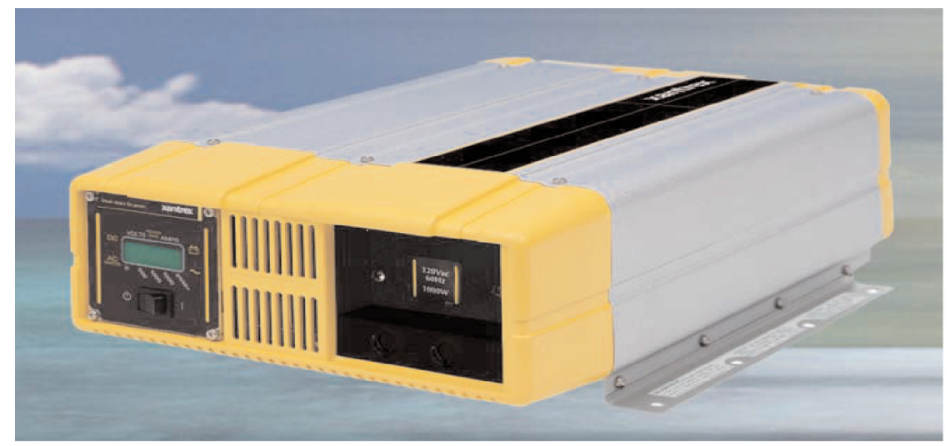

Hình 4: Bộ đổi nguồn điện

Một bộ đổi nguồn điện sử dụng để chuyển đổi 28 vôn DC nguồn điện máy bay đến nguồn 120 vôn $\mathrm{AC}$ được sử dụng bởi TAGS. Đầu ra bộ đổi nguồn sử dụng một ổ cắm tiêu chuẩn 3 chân Bắc Mỹ để phù hợp với các dây điện cung cấp với hệ thống.

\section{3.d. Khung hệ thống}

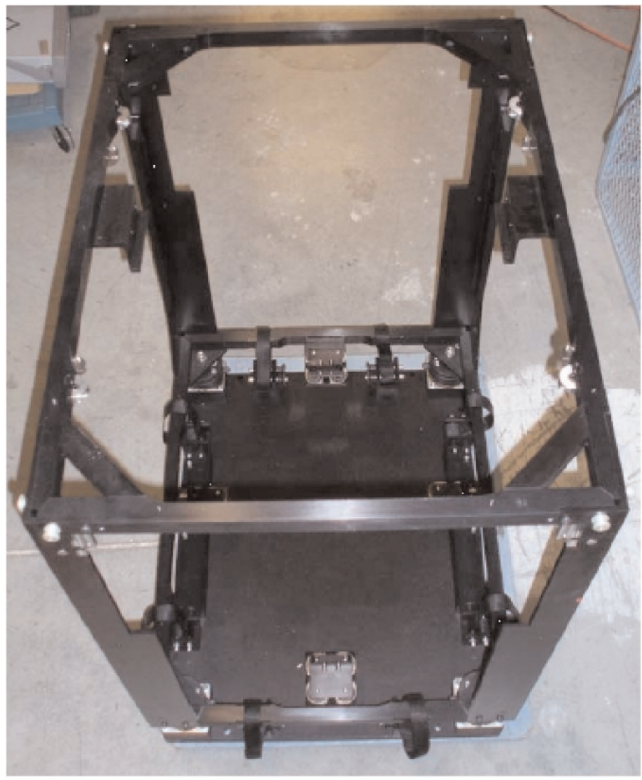

Hình 5: Khung hệ thống TAGS

Vì khi bay máy bay rung lắc mạnh nên khung máy TAGS đã được thiết kế với các khớp đa năng và cảm biến trên hệ thống dây treo khép kín cùng dầu giảm chấn và đế máy có đệm không khí để chống rung.

Nguồn cung cấp điện là bộ lưu dòng (UPS) được định vị trên giá đỡ cố định của hệ thống khung. Trong thời gian bay UPS nhận 120 vôn AC từ bộ đổi nguồn điện. Khung hệ thống cũng được kết nối nguồn điện, các mô đun điều khiển và máy tính để tính thời gian thu thập dữ liệu GPS. Hệ thống khung được bắt bu lông chắc chắn trên giá đỡ cố định. 
2.3.e. Khớp cân bằng đa năng

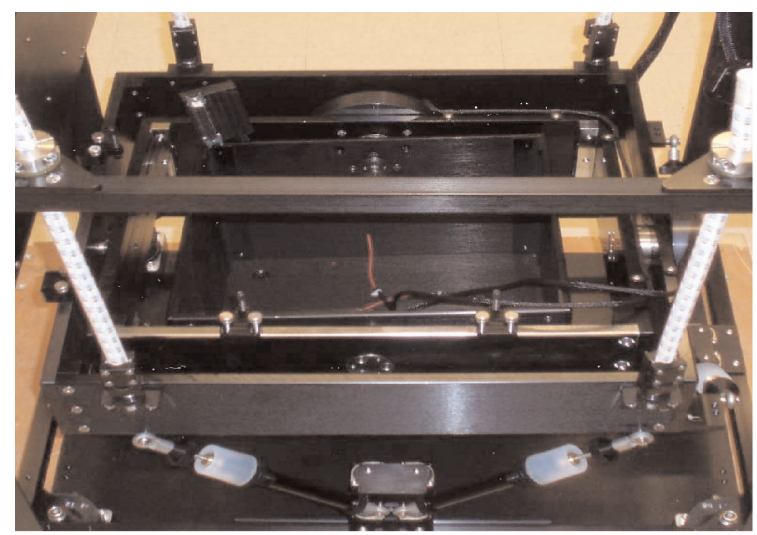

Hình 6: Khớp cân bằng đa năng

Khớp cân bằng đa năng có chứa cảm biến đo trọng lực và tự động giữ nó nằm ngang khi hệ thống chuyển động. Khớp đa năng có thể quay theo 2 hướng: góc nghiêng và xoay tròn được gọi là trục ngang và trục dài treo trên TAGS. Cảm biến được giữ ngang bằng việc sử dụng bộ điều chỉnh hệ thống thông tin phản hồi, kiểm soát bởi bảng điều khiển. Gia tốc kế và con quay hồi chuyển được sử dụng trên mỗi trục để xác định vị trí nằm ngang và đo góc quay ngang. Động cơ mô men xoắn trên cả 2 trục được dùng để điều chỉnh và giữ thăng bằng khớp cân bằng đa năng.

\section{3.f. Cảm biến đo trọng lực}

Đây là bộ phận quan trọng nhất thực hiện các phép đo trọng lực hàng không bao gồm cảm biến trọng lực, bộ tản nhiệt cùng với các thiết bị điện tử để điều khiển cảm biến và đo vị trí nằm ngang của thiết bị. Tín hiệu được thu thập và xử lý bởi các mô đun điều khiển và hiển thị trên màn hình hoặc máy tính bên ngoài.

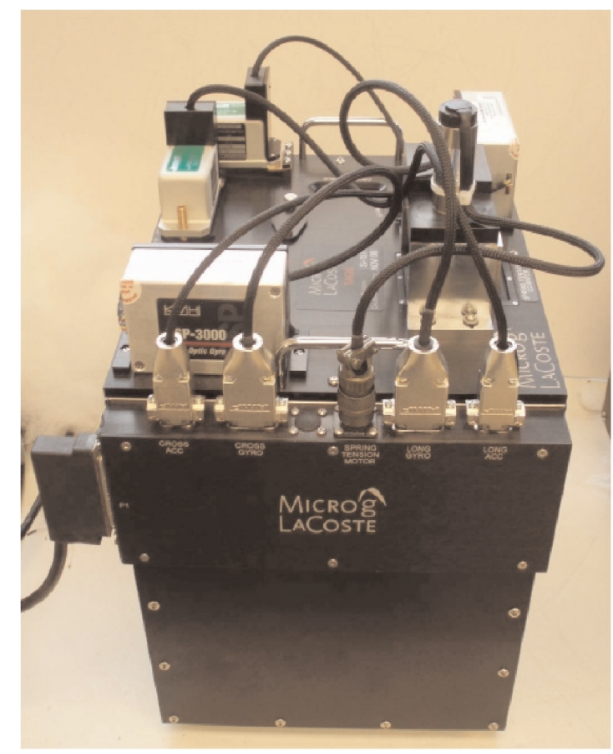

Hình 7: Bộ phận cảm biến đo trọng lực hàng không 


\section{3.g. Các thiết bị ngoại vi}

TAGS được đặt trên bộ khung với bàn phím, màn hình và con chuột đi kèm, thường được sử dụng để hiển thị và cung cấp cho người sử dụng thông tin đầu vào của hệ thống. Ngoài có thể dùng bàn phím và chuột để điều khiển quá trình đo đạc từ bên ngoài. Hệ thống được cung cấp một máy tính đăng nhập dữ liệu để thu nhận các tập tin dữ liệu dự phòng như là một bản sao lưu cho hệ thống chính và cũng có thể được sử dụng để kiểm soát hoạt động của các phần mềm sau khi hệ thống chạy.

Có thêm một nguồn điện bổ sung cho bộ cấp nhiệt để giữ cho nhiệt độ cảm biến được ổn định khi điện nguồn không có hoặc bộ cảm biến được tháo ra khỏi hệ thống.

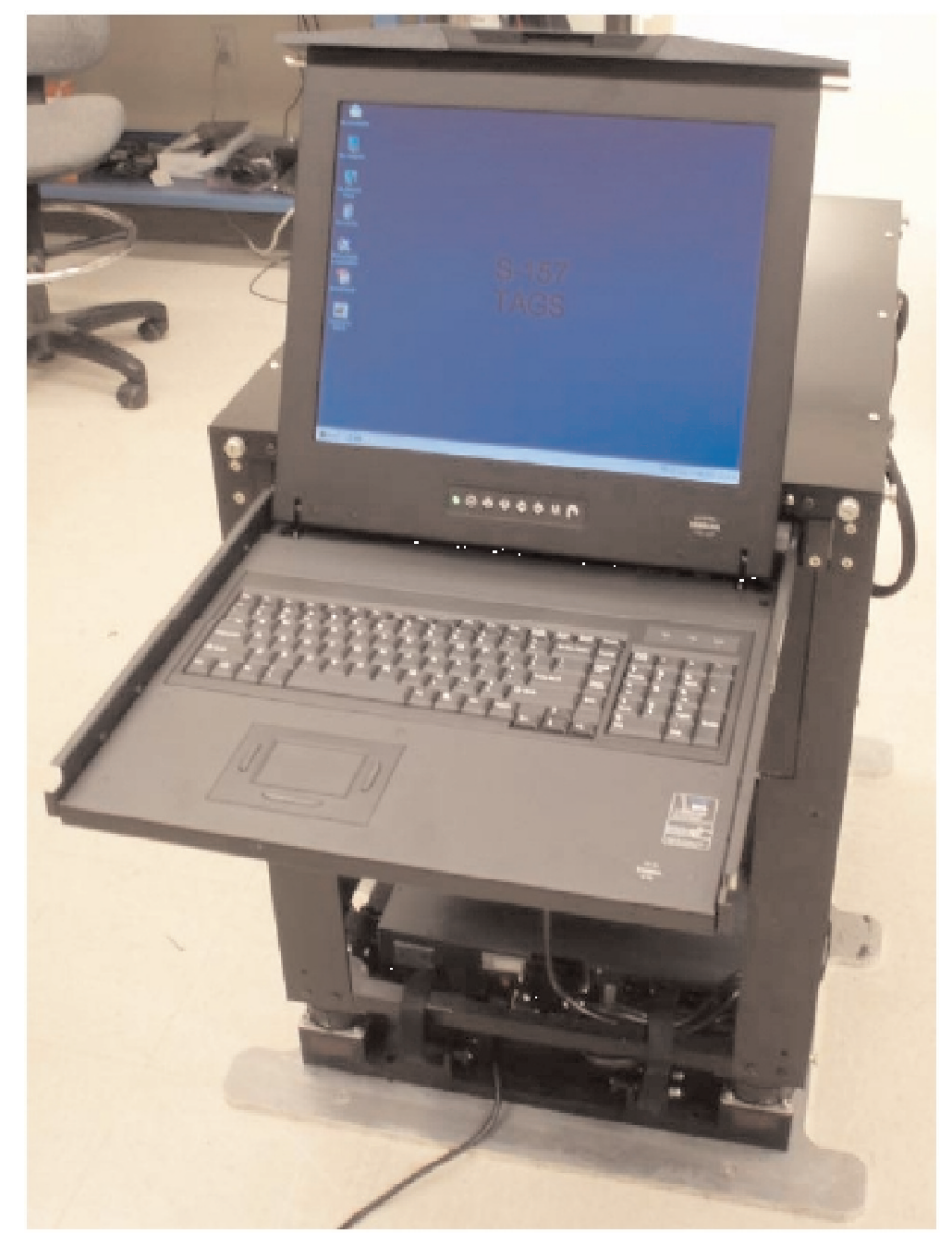

Hình 8: Bộ điều khiển (bàn phím, chuột, màn hình) trên TAGS

(Xem tiếp số 19 tháng 3/2014) 